\title{
Implementation and evaluation of the Heffter Method to calculate the height of the planetary boundary layer above a southern Great Plains site
}

\author{
Igor Pesenson \\ November $30^{\text {th }}, 2002$
}

\begin{abstract}
This paper explores the Heffter Method -- an algorithm for finding the height of the Planetary Boundary Layer (PBL). The algorithm is applied to the Balloon Borne Sounding System (BBSS) data collected over the Southern Great Plains (SGP) Site of the Atmospheric Radiation Measurement (ARM) Program. After discussing the successes and shortcomings of the algorithm, the resulting PBL height estimates for dates in May of 2002 are related to $\mathrm{CO}_{2}$ concentration and wind data. The $\mathrm{CO}_{2}$ data used is from the Precision Gas System (PGS) while the wind data is a combination of data from the Portable $\mathrm{CO}_{2}$ Flux System on the SGP site and BBSS.
\end{abstract}




\section{Introduction}

Although all of the troposphere (the lower $\sim 10 \mathrm{~km}$ of the atmosphere) is effected by surface conditions, most of it has a relatively slow response time. The lower part of the troposphere that is effected on a shorter time scale is commonly defined as the Planetary Boundary Layer (PBL). According to Stull (1), one can describe the planetary boundary layer as "that part of the troposphere that is directly influenced by the presence of the earth's surface, and responds to surface forcings with a timescale of about an hour or less."

Surface temperature has a strong relationship with height of the PBL. As the surface cycles between daytime radiation and nighttime cooling the amount of convection taking place changes. When the temperature gradient is steep, more convection takes place to dissipate thermal energy in the most efficient manner. In other words, the greater the temperature difference between the surface and the lower troposphere, the higher convective eddies must reach to alleviate the gradient. Relating this to Stull's definition of turbulence, it can be concluded that the height of the PBL varies with surface temperature. In fact, the spatial range of the PBL can vary from less than one hundred meters to several kilometers.

The strong relationship between convective turbulence and height of the PBL is sometimes used to define the boundary layer (1) and call it the Convective Boundary Layer (CBL). Analogous to the Stull's definition but focusing on turbulence, Lloyd et all (3) describe $\mathrm{CBL}$ as "a layer of air typically of order $1 \mathrm{~km}$ in depth, well mixed by turbulence maintained by buoyancy due to heating at the ground. It is bounded above by stably stratified, nonturbulent air and grows through the day".

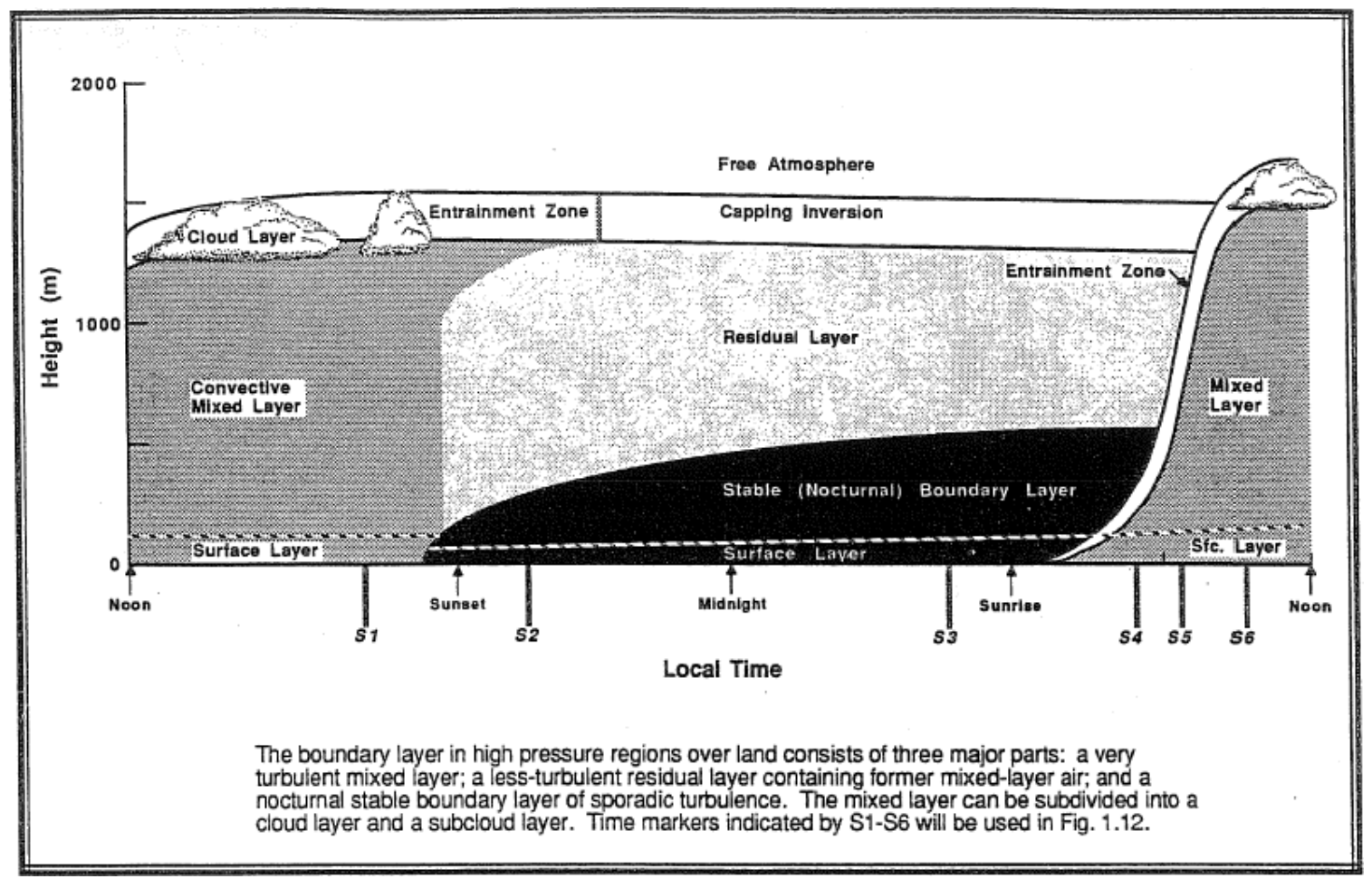

Figure 1. Taken from R. B. Stull, An Introduction to Boundary Layer Meteorology.

The PBL is also broken down into several layers (Figure 1). The lowest part of the PBL is the Surface Boundary Layer and it is directly in contact with the ground. It is characterized by "strong vertical gradients in temperature, humidity, wind and scalars" and it is roughly $10 \%$ of the PBL $(1,2)$. Immediately above the Surface Boundary Layer is the Mixing Layer (ML). This 
layer is dominated by convective mixing and any existing wind is almost constant in profile (1) (Figure 2). The top of the ML, as described by Lloyd, is bounded by stratified wind shear. This "layer at the top of the ML acts as a lid to the rising thermals, thus restraining the domain of turbulence" (1). This is called the Entrainment Zone and an absolute temperature inversion is frequently present here. Because of this, it can be also be referred to as the Inversion Layer.

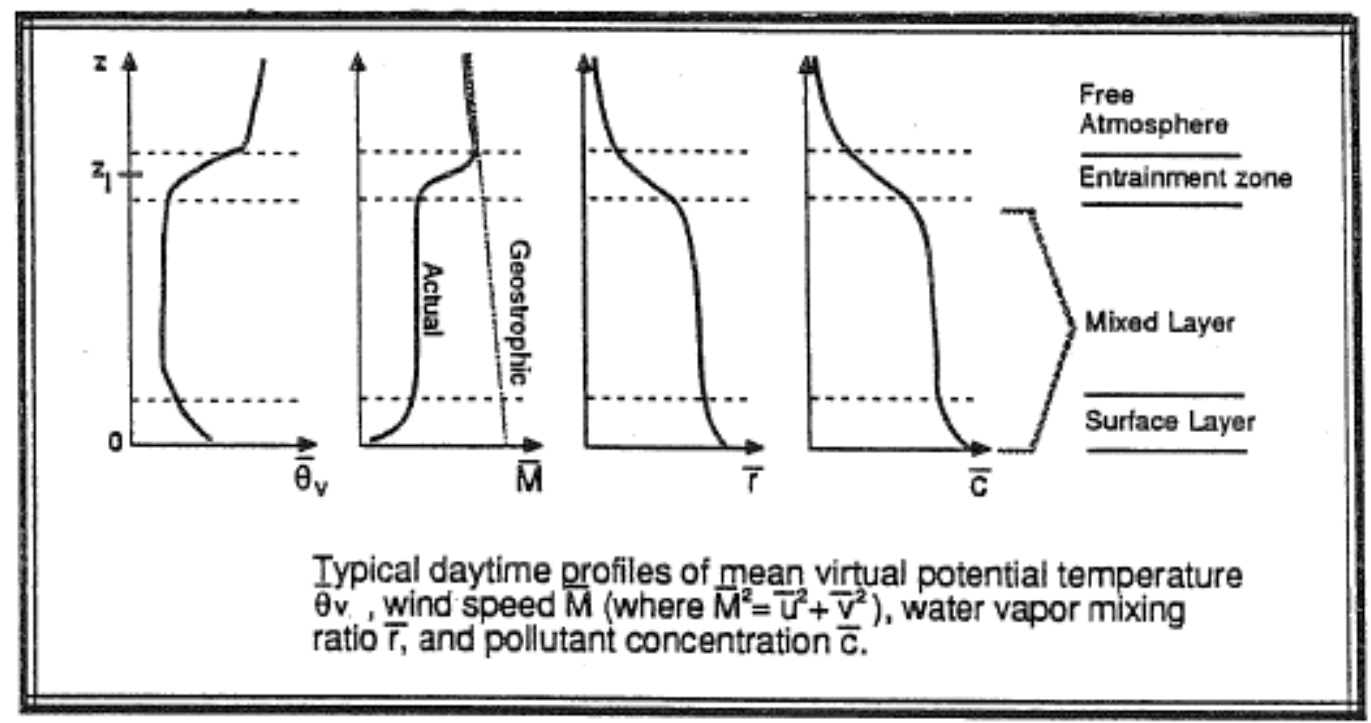

Figure 2. Taken from R. B. Stull, An Introduction to Boundary Layer Meteorology.

\section{Heffter Method}

The Heffter Method relies on the existence of the Inversion Layer described above. It consists of two mathematical conditions that attempt to identify a "critical inversion" in the temperature profile. Although "inversion" in the term "Inversion Layer" refers to increase of absolute temperature with height, the technique uses potential temperature to find the top of the PBL. The two conditions are

$$
\begin{aligned}
& \Delta \theta / \Delta z>0.005{ }^{\circ} \mathrm{K} \mathrm{m}^{-1} \\
& \theta_{t}-\theta_{b}>2{ }^{\circ} \mathrm{K}
\end{aligned}
$$

where $\Delta \theta / \Delta z$ is the potential temperature lapse rate in the inversion layer and $\theta_{\mathrm{t}}, \theta_{\mathrm{b}}$ refer to the potential temperatures at the top and bottom of the critical inversion layer, respectively.

The first condition (Eq.1) looks for a significant change in potential temperature. Potential temperature $\theta$ is the temperature a packet of air would have if it were brought down to sea level.

$$
\theta=\mathrm{T}\left(\mathrm{P}_{0} / \mathrm{P}\right)^{\mathrm{R} /(\mathrm{mCp})}
$$

$\mathrm{T}$ is the dry air temperature, $\mathrm{P}_{0}$ is the standard pressure, and $\mathrm{R} /(\mathrm{mCp})$ evaluates to .286 . Potential temperature is more or less constant inside the mixed layer due to adiabatic mixing. According to the Ideal Gas Law

$$
\mathrm{PV}=\mathrm{nRT}
$$

the decrease in pressure with height leads to the increase in volume, which, in turn, decreases the absolute temperature of the air packet. Potential temperature (Eq. 3) takes the effect of pressure out so as to let us to focus on the energy of an air packet. As the height increases and the entrainment zone is entered, the air is no longer well mixed, the adiabatic assumption is no longer as effective, and so potential temperature starts increasing with height (Figure 4). 
The second condition (Eq.2) attempts to ensure the height of the PBL is set at the top of the Inversion Layer, not merely the top of the Mixing Layer (Figure 2).

\subsection{Algorithm Implementation}

The Heffter algorithm was implemented in C programming language and (see Appendix for full text of program). The code stepped through the data set and checked the validity of Equation (1). As soon as Equation (1) was satisfied, equations (1) and (2) would be checked for each step through the data. If both were simultaneously true, the PBL height for the data set was output. If condition (1) became, at first, satisfied but then failed before (2) was satisfied, the program continued to check for condition (1) at the current height and above.

It was found that this straightforward implementation of the method failed rather frequently. Many of the data sets had trouble satisfying exactly these conditions, despite coming close. It became clear that one or both of the conditions had to be somewhat more flexible. Condition two (Eq. 2) was chosen as the one to be iteratively relaxed on algorithm failure below 3000 meters. There was no reason for why condition (2) should have been picked over conidition (1), the iterative relaxation could have been applied to either. And so the code, upon having failed to satisfy both conditions on all data below 3000 meters, iteratively lowered the $2.0^{\circ} \mathrm{K}$ condition by $0.1{ }^{\circ} \mathrm{K}$ until both Eq. 1 and modified Eq. 2 were satisfied.

\subsection{Algorithm Performance}

For each sonde balloon launch both absolute humidity and potential temperature were plotted against height. Absolute humidity decreases slowly within the Mixed Layer and the top is marked by a sharp moisture decrease. This fact is often used together with potential temperature to identify top of PBL (1). The performance of the Heffter Method was evaluated via visual inspection of plots of theta and absolute humidity for each BBSS data set.

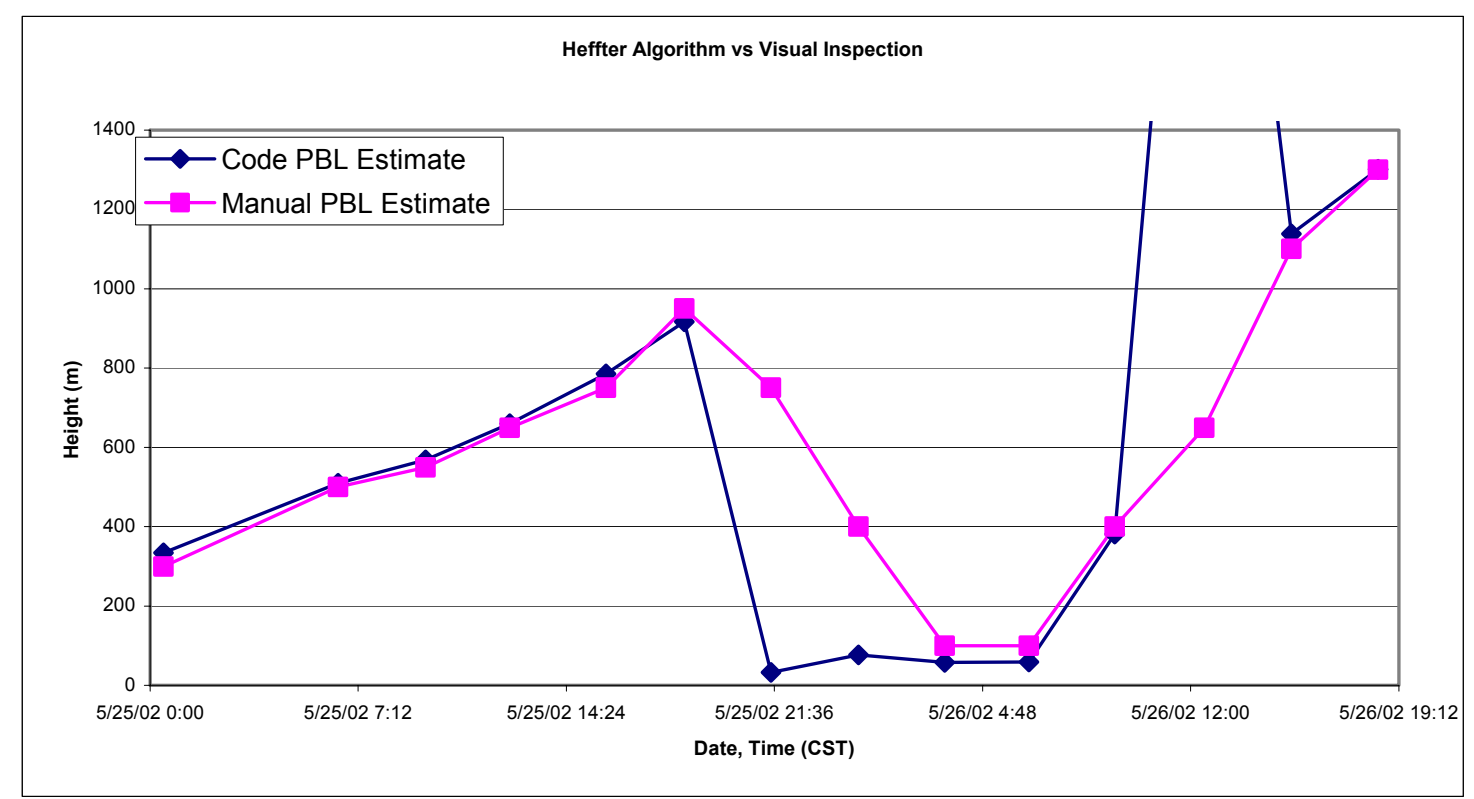

Figure 3. The dark line is the evolution of the PBL as estimated by the slightly modified Heffter Method. The lighter line is the evolution of the PBL as determined by individually inspecting each data set. Note that manual PBL height on May $26^{\text {th }}$ at 03:29 AM and 06:24 AM (CST) was artificially placed at $100 \mathrm{~m}$ due lack of definition in the theta and humidity plots for this time. 
The algorithm performed quite well under reasonable weather conditions. Figure 3 shows fourteen balloon launches in two days. Out of the fourteen PBL estimates, the program was significantly off three times. The first two points the program stumbled upon, were May $25^{\text {th }}$ and May $26^{\text {th }}$ at 21:29 and 00:30 local time (CST), respectively. These two points, as well as the two following, occurred during nighttime when the PBL is not well defined. Figure 5 shows the profiles of theta and absolute humidity for May $25^{\text {th }}, 21: 29$ local time. The graph shows a welldefined mixed layer, much as in Figure 4, however, the base of the graph had already started to change. Ground cooling had begun to alter the lower Surface Boundary Layer. The code correctly found the Heffter conditions to be satisfied at $33 \mathrm{~m}$ and never bothered to check that most of the PBL was still in tact this early in the evening. According to Figure 1 this welldefined layer could be considered part of the Residual Zone and so not part of the PBL. It is unclear exactly what can be called the PBL in this case and visual analysis, relying on the water profile, placed it close to 400 meters. The same problem was responsible for the May $26^{\text {th }}, 00: 30$ difference between calculated and estimated values. It can be concluded that one shortcoming of the algorithm might be underestimation of the PBL in the evening, when there is a strong residual layer.

The following two graphs of potential temperature and absolute humidity, on May $26^{\text {th }}$ at 03:29 and 06:24, demonstrate a different issue. Figure 6 shows the lack of definition for the 03:29 (CST). The Heffter conditions were satisfied at 58 meters, and this is where the program placed the PBL. As a convenient minimum, the visual analysis placed the PBL at $100 \mathrm{~m}$ under such ambiguous circumstances.

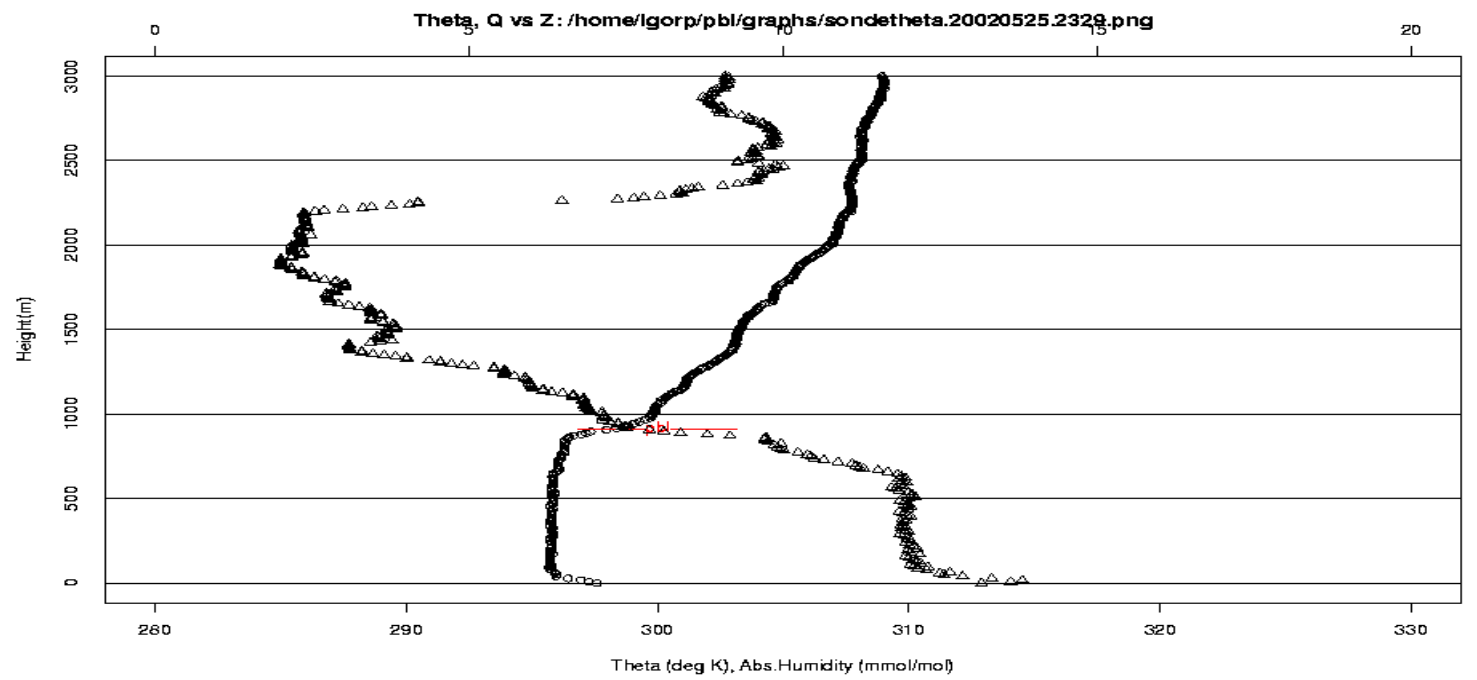

Figure 4. Potential temperature and absolute humidity at 06:30PM local time (CST) on May 25th. The surface boundary layer, the mixed layer, and the inversion layer are all well defined. 


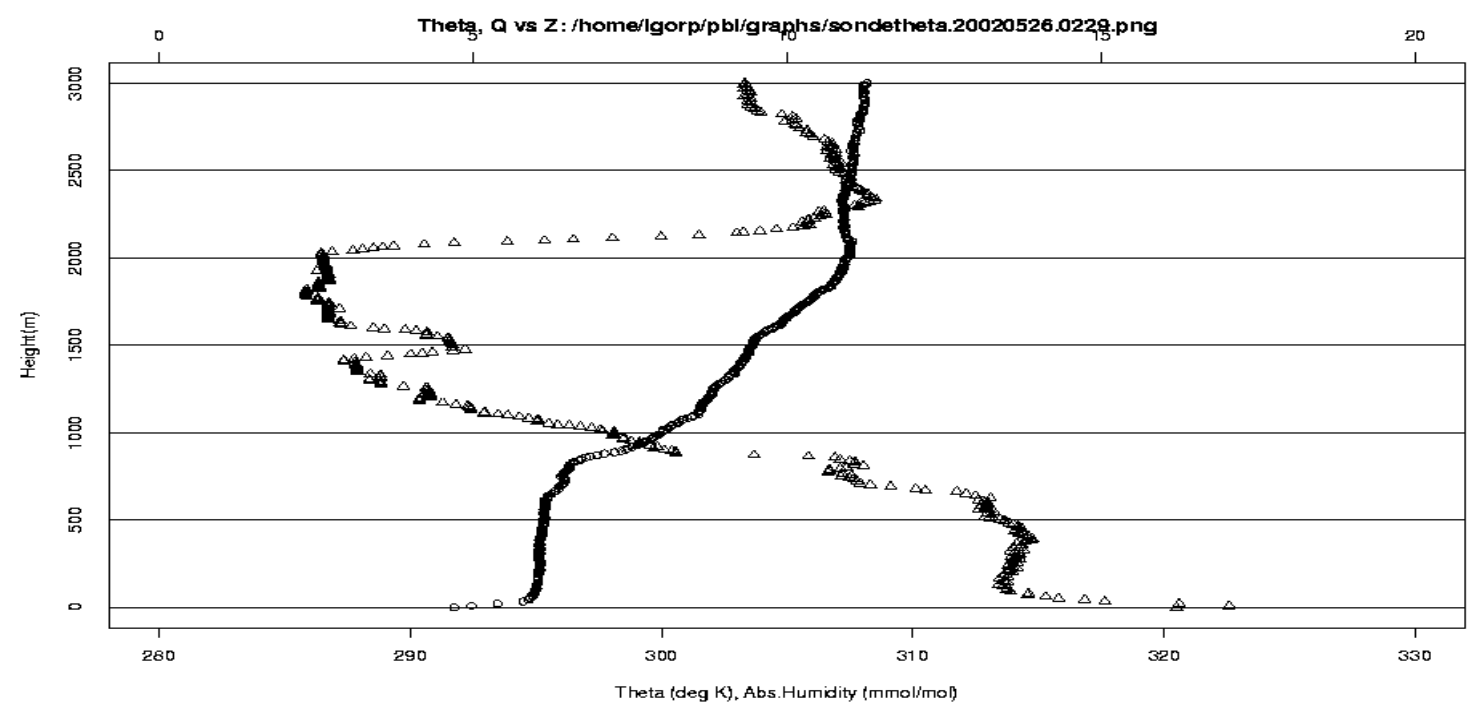

Figure 5. There is a strong residual layer up to 9:29PM local time (CST) on May 25th. The temperature profile reversal is seen in the first $100 \mathrm{~m}$, but not above. This makes it tempting to place the PBL height at around $750 \mathrm{~m}$, despite the change in water profile close to $400 \mathrm{~m}$. Visual analysis settled on $400 \mathrm{~m}$ as the PBL height.

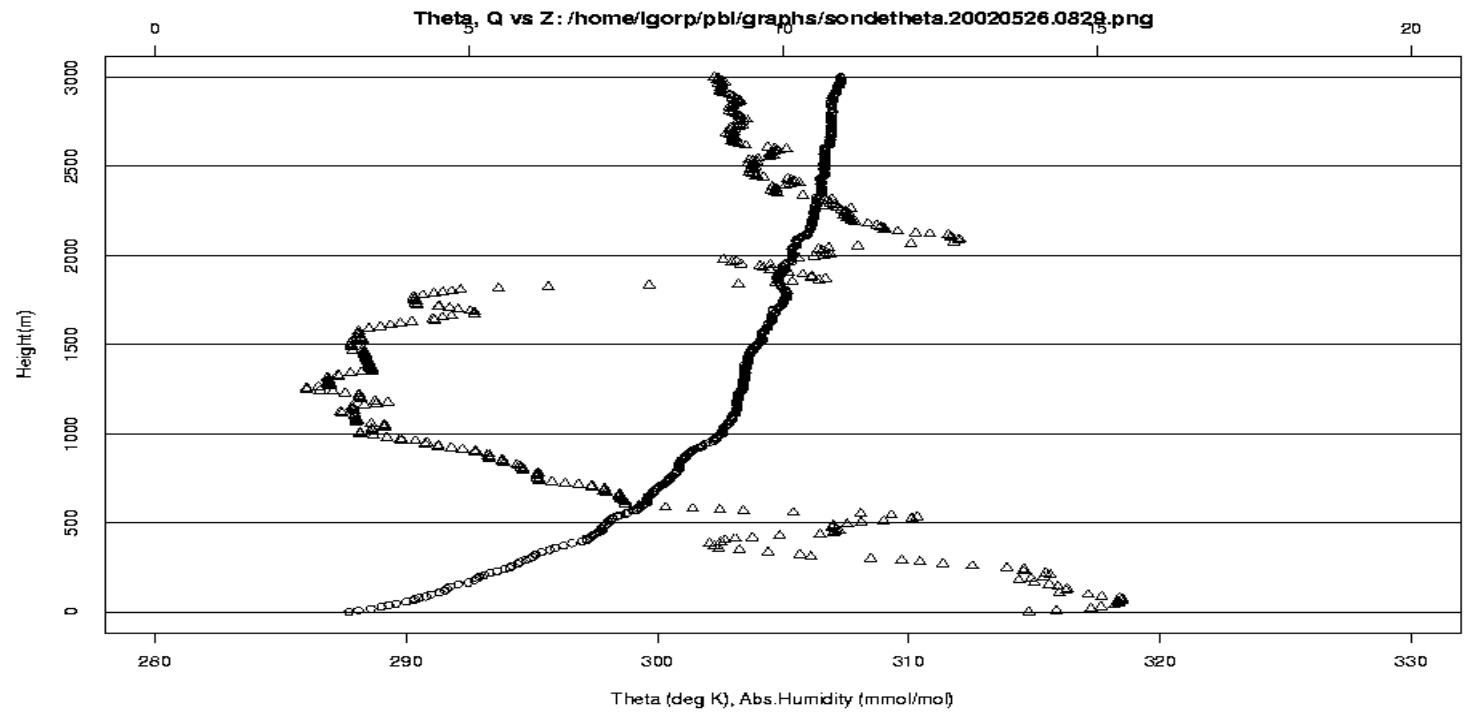

Figure 6. Potential temperature profile lacks definition and the Heffter method finds PBL to be at $58 \mathrm{~m}$.

The May $26^{\text {th }}, 03: 29$ and 06:24 (CST) points reflect the ambiguity of the PBL late into the night. It is badly defined so that even visual analysis cannot place the PBL better than the algorithm. However, even if the PBL is badly defined at such times, the program still calculates a height with consistent conditions. Although this might not be identified as the height of the PBL, it is still arguably a useful point due to the consistency with which it is calculated.

\section{Correlation of PBL and CO2}

Precision Gas System is a data collection system mounted on a sixty-meter tower located at the Cloud and Radiation Testbed (CART) of the ARM Southern Great Plains Site (SGP). The sensors are mounted at $2 \mathrm{~m}, 4 \mathrm{~m}, 25 \mathrm{~m}$, and $60 \mathrm{~m}$ and $\mathrm{CO} 2$ concentration is measured as well as 
some other variables. Analysis of the relationship between $\mathrm{CO}_{2}$ measurements and PBL height demonstrates some predictable, yet interesting, results.

Strong convective mixing during the day raises the height of the PBL up to 1.8 kilometers. Daytime radiation that is responsible for increase in convective activity also stimulates photosynthesis. This causes the $\mathrm{CO}_{2}$ concentrations to drop at sunrise and decrease through to sunset (Figure 6). During this time there seems to be little discrepancy between concentrations at 2 and 60 meters and so both heights can be assumed to be in the well-mixed layer.

At sunset, the surface temperature drops and convection is no longer the dominant energy transport mechanism. Photosynthesis has stopped and $\mathrm{CO}_{2}$ begins accumulating due to ground respiration. The surface boundary layer is the first to be affected and a temperature inversion can be detected there early in the evening (Figures 4 and 5). Figure 7 also points out that 2 meter $\mathrm{CO}_{2}$ response time to sunset is much quicker than at 60 meters. The atmosphere is no longer well mixed by convection and the concentration gradients become steeper. As the evening progresses, the PBL height drops to much lower levels, often leaving a residual layer higher up (Figure 1).

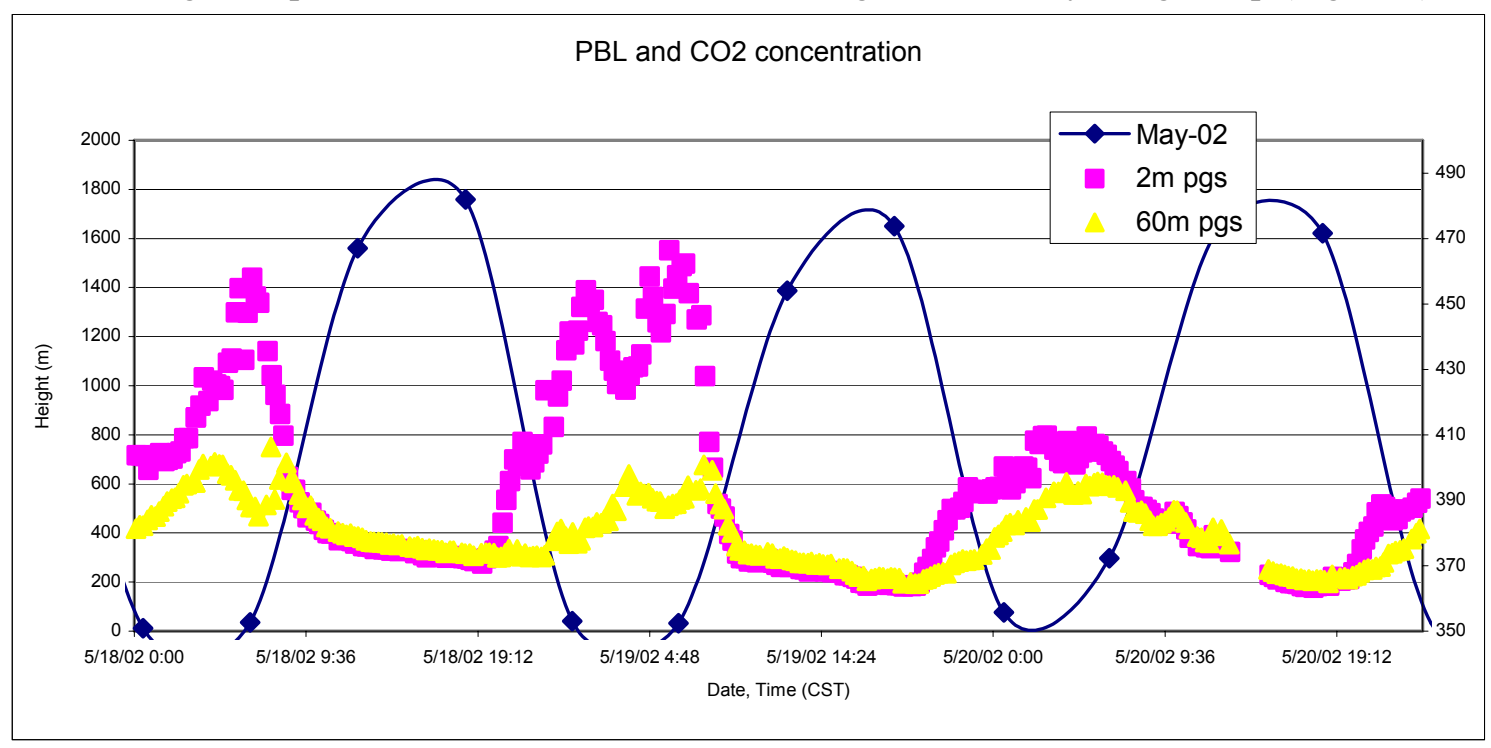

Figure 7. There is a strong nighttime decoupling between $2 \mathrm{~m}$ and $60 \mathrm{~m} \mathrm{CO} 2$ concentrations.

Another issue behind the increase in nighttime $\mathrm{CO}_{2}$ concentrations is the rectifier effect (5). One can think of the PBL as the top of a "box" of air. This box has a certain concentration of some gas. During the nighttime the top of the box, or the height of the PBL, will lower. Ignoring any photosynthesis or ecosystem respiration effects, the concentration of the gas will increase following the Ideal Gas Law. Although the PBL is not a perfectly sealed box, and the situation is affected by photosynthesis and ecosystem respiration, the effect should still be noticed on trace gas concentrations. The nighttime PBL height on May $20^{\text {th }}$ is one to two hundred meters higher than that for previous night of May $19^{\text {th }}$ (Figure 6). The coupling between $2 \mathrm{~m}$ and $60 \mathrm{~m}$ is clearly much stronger during night of May $20^{\text {th }}$ than either May $18^{\text {th }}$ or $19^{\text {th }}$. As there could not have been any photosynthesis on either night, the change in readings must have originated from different atmospheric conditions. It is not certain whether a higher PBL was solely responsible for lower concentrations on this night, but the two are correlated.

\section{Wind and PBL}

Since the height of the PBL depends on air temperature, it is logical to postulate a relationship between wind and PBL. The vertical velocity and temperature of wind could affect 
the air temperature and pattern of mixing. The wind temperature should be related to its general direction: warmer wind should generally come from the south.

Wind speeds are much higher during the day and die down at night. This is, of course, attributed to temperature gradients established by daytime radiation. By this reasoning, higher daytime PBL should correspond to faster winds, as both are caused by high heat gradients. This is roughly the relationship observed in Figure 8. However, if the horizontal length scale of the temperature gradients is larger than that of the BBSS data set, the relationship can be expected to be more complex.

The data under scrutiny points to this later case of a complex relationship. For example, the PBL height close to 00:00 on May $20^{\text {th }}$ is $100-200$ meters higher than that on May $19^{\text {th }}$.

However, the wind speeds for both nights are comparable. This is in contrast to the night of May $18^{\text {th }}$ when a much higher gas concentration at $2 \mathrm{~m}$ seems to correlate well with almost zero wind speed at $4 \mathrm{~m}$.
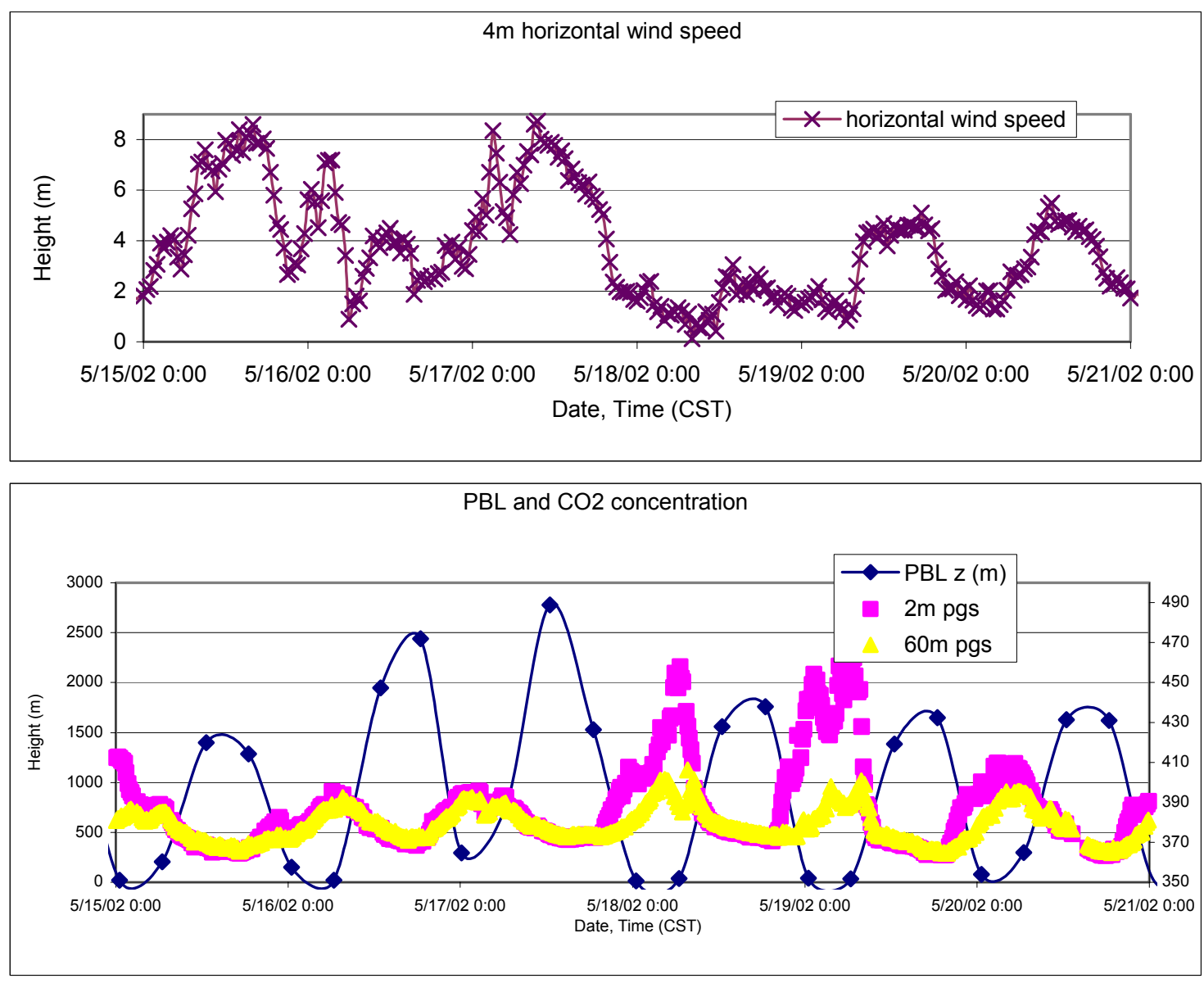

Figure 8 . The correlation between horizontal wind speeds at $4 \mathrm{~m}$ and $2 \mathrm{~m} \mathrm{CO}_{2}$ concentration is not very consistent.

To explore the inconsistency between the nighttime PBL height and wind speed during the nights of May $18^{\text {th }}, 19^{\text {th }}$, and $20^{\text {th }}$, we can look at wind direction. Southern wind, generally warmer, should result in higher PBL heights, whether as northern wind might bring in cold air and drop the PBL. Figure 9 shows directions of the wind at the end of these three nights. May $18^{\text {th }}$, with a rather low calculated PBL height is dominated by wind coming from the north. May $19^{\text {th }}$, also with a low calculated PBL height, has consistent wind from the south. This contradiction is further underlined by wind direction of May $20^{\text {th }}$. The PBL height was calculated 
higher then both May $18^{\text {th }}$ and $19^{\text {th }}$, but the wind was more eastwardly than the May $19^{\text {th }}$. The conclusion, at least for these particular dates, is that the relationship between wind and nighttime PBL is more complex than postulated.

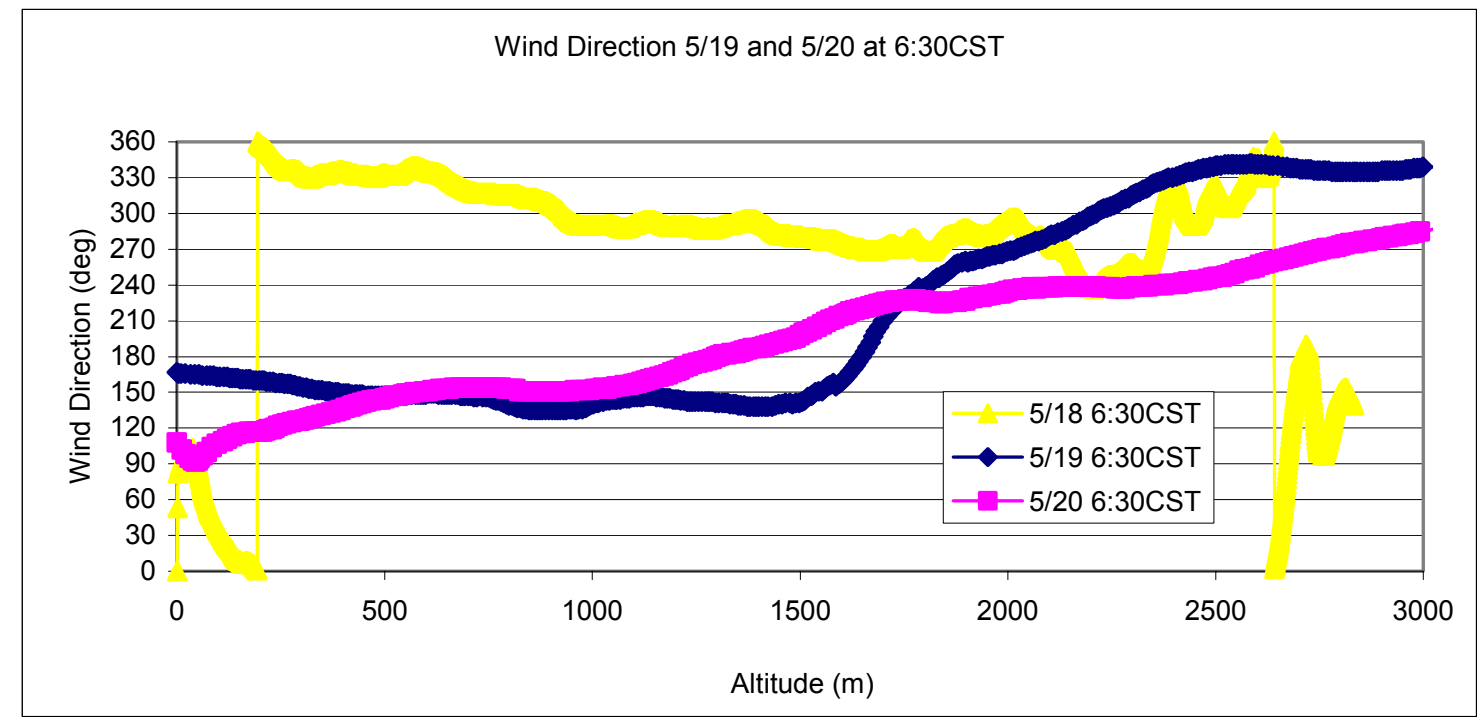

Figure 9. Wind direction at 6:30 CST on 5/18,5/19, 5/20. Zero degrees denotes wind coming from the north, while 90 degrees is wind coming from the east. Despite having a north dominated wind on $5 / 18$, the nighttime PBL was estimated higher than on 5/20.

\subsection{Conclusions}

Although there are difficulties in applying the Heffter Method to balloon sonde data, it is a good starting point. There are several modifications one might want to consider in implementing the algorithm:

a) Just as the condition two is iteratively relaxed on failure, have condition one relaxed on failure. Whether to do this before, after, or intermixed with relaxing of condition two is an issue requiring more analysis.

b) Add another technique to attempt to detect a sharp change in $d(\Theta) / d z$. Bill Riley suggested fitting a parabola to small, "mirrored", snippet of $\Theta$ vs. height plot. As soon as the curvature becomes significant, note. This could be weighed together with other eligible points as determined by Heffter Technique.

c) Instead of picking the first point that you find as PBL, create an array of several eligible ones by running through the data several times. Then pick the best one by applying pre-determined criteria. 


\section{Bibliography}

(1) Stull, R. B. An Introduction to Boundary Layer Meteorology, Kluwer Academic Publishers, 1993.

(2) Lecture notes, Earth and Planetary Science 129, Biomeorology, Fall 2002, Dennis Baldocchi.

(3) Lloyd, J., Francey, R.J., Mollicone, D., et all, Vertical Profiles, Boundary Layer Budgets, and Regiounal Flux Estimates for CO2 and its $C-13 / C-12$ ratios and for water vapor above a forest/bog mosaic in central Siberia, Global Biogeochemical Cycles, Jun 2001, V15(N2):267-284.

(4) Heffter, J. L., 1980: Transport layer depth calculations. Second Joint Conference on Applications of Air Pollution Meteorology, New Orleans, LA (1980).

(5) Denning, A.S., Takahashi, T., Friedlingstein, P., Can a strong atmospheric $\mathrm{CO}_{2}$ rectifier effect be reconciled with a "reasonable" carbon budget?, Tellus Series B - Chemical and Physical Meteorology, Apr 1999, V51(N2):249-253.

\section{Acknowledgement}

This work was supported by the Atmospheric Radiation Measurement Program, Biological and Environmental Research, Office of Science, U.S. Department of Energy under Contract No. DE-AC03-76SF00098. The author would also like to thank Margaret Torn and Marc Fischer. 


\section{Appendix}

The complete text of the program used to implement the Heffter Method is given below:

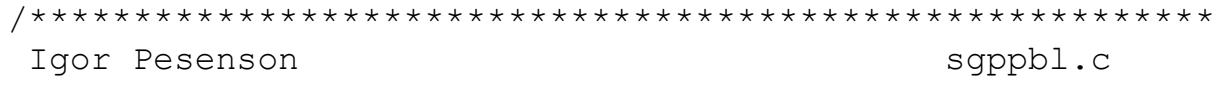

b) Data is analyzed through using the original Heffter constraints. If no point is found to satisfy them below PBLMAX, the second constraint, theta difference of $2 \mathrm{~K}$ is relaxed by heffter delt inc (currently.1). The data is then analyzed up to PBLMAX again. The seccond condition keeps getting iteratively reduced as low as possible $(>0)$. If still no point is found, a failure message is displayed.

Input:

None. The program read the file "/home/igorp/pbl/pbl-inputfiles.txt" This file has to list the file names of the sonde files to be analyzed, in order. The program finds the files in /data/armarchive/sonde/al opens them one by one and reads the cdf data.

In the future, it might be easier to change the program to so that a date range can be input on command line and the files would be pulled automatically.

Output:

Output is to a file currently named "/home/igorp/pbl/pbloutput.csv". For each input file, the program outputs a line into the output file containing the following:

year,jday, hhmm, z PBL (m), tdry at pbl (deg C), pres at pbl (mbar), ave $q$ from 0 to pbl ( $/ / \mathrm{m} 3)$, ave q from (pbl+500) to (pbl+1000) (g/m3), ave q from $(\mathrm{pbl}+500)$ to $(\mathrm{pbl}+2500)(\mathrm{g} / \mathrm{m} 3)$, ave rh from 0 to pbl (\%), ave rh 
from (pbl+500) to (pbl+1000) (\%), ave rh from (pbl+500) to (pbl+2500) $\left(\frac{\circ}{\circ}\right)$, ave tdry from 0 to pbl (deg C), ave tary from (pbl+500) to $(\mathrm{pbl}+1000)$ ( $\operatorname{deg} \mathrm{C})$, ave tdry from (pbl+500) to (pbl+2500) (deg C)), ave pres from 0 to pbl (mbar), ave pres from (pbl+500) to (pbl+1000)

(mbar), ave pres from (pbl+500) to (pbl+2500) (mbar)

Revisions:

r4 - standardized input and output and cleaned up the code some.

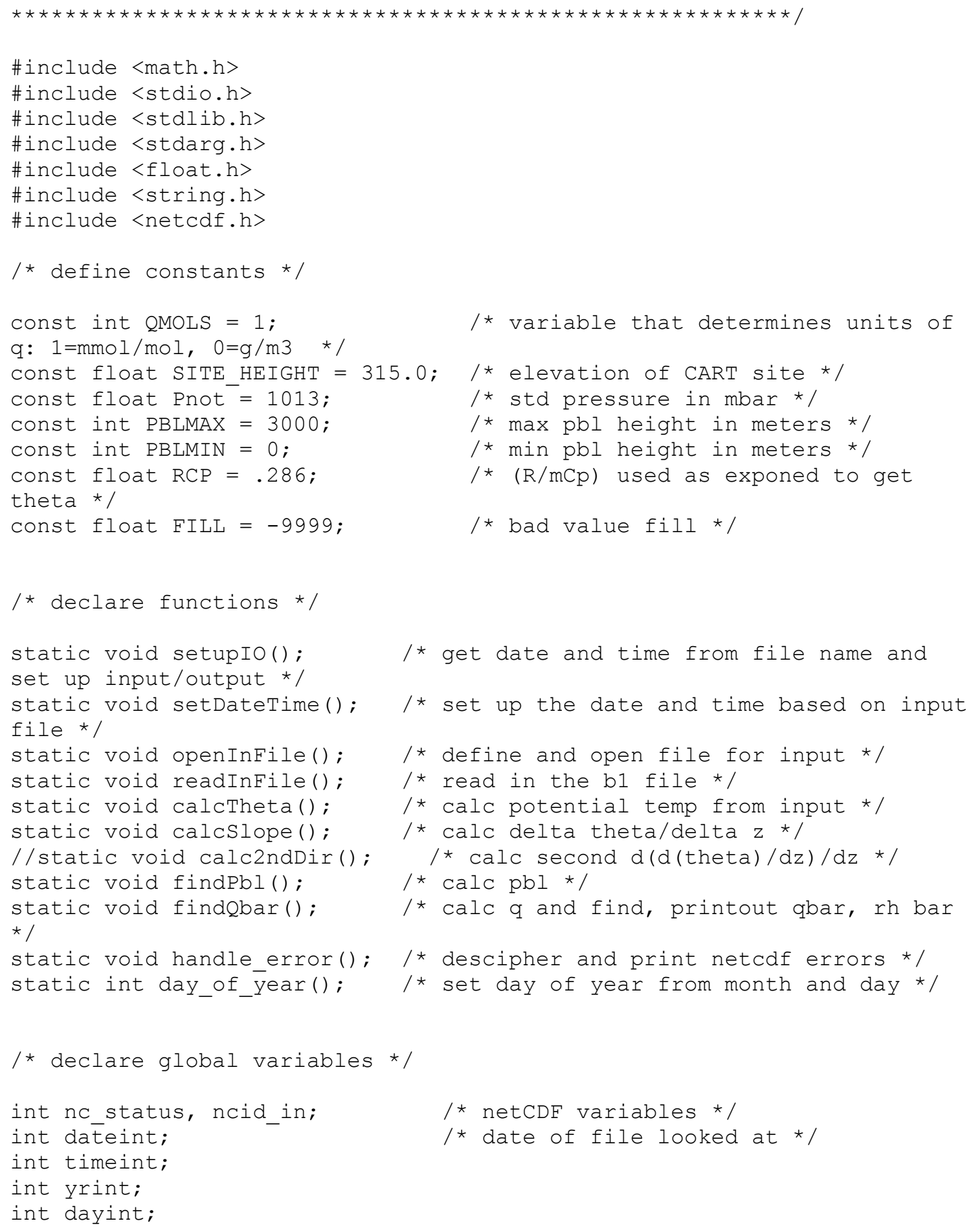




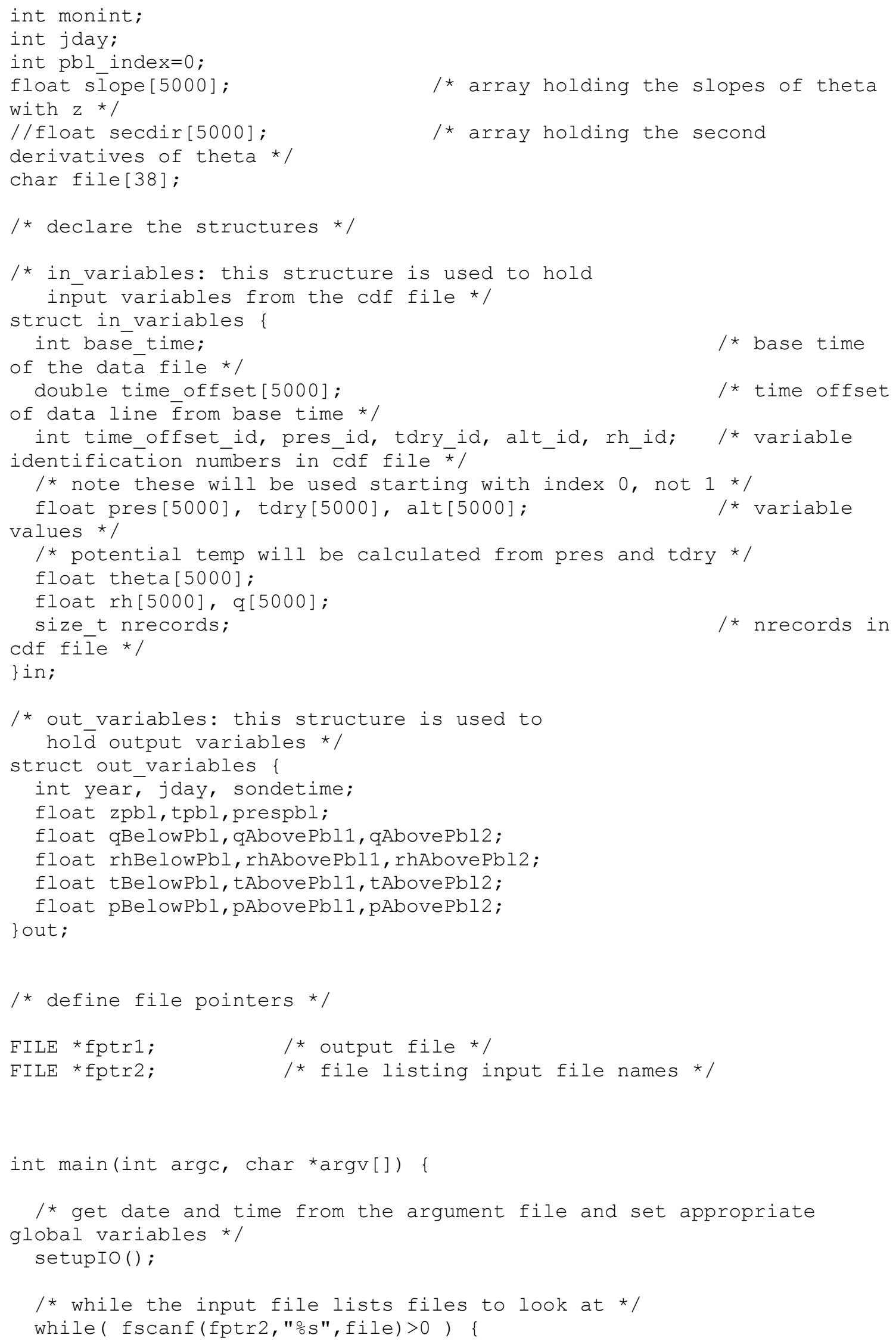




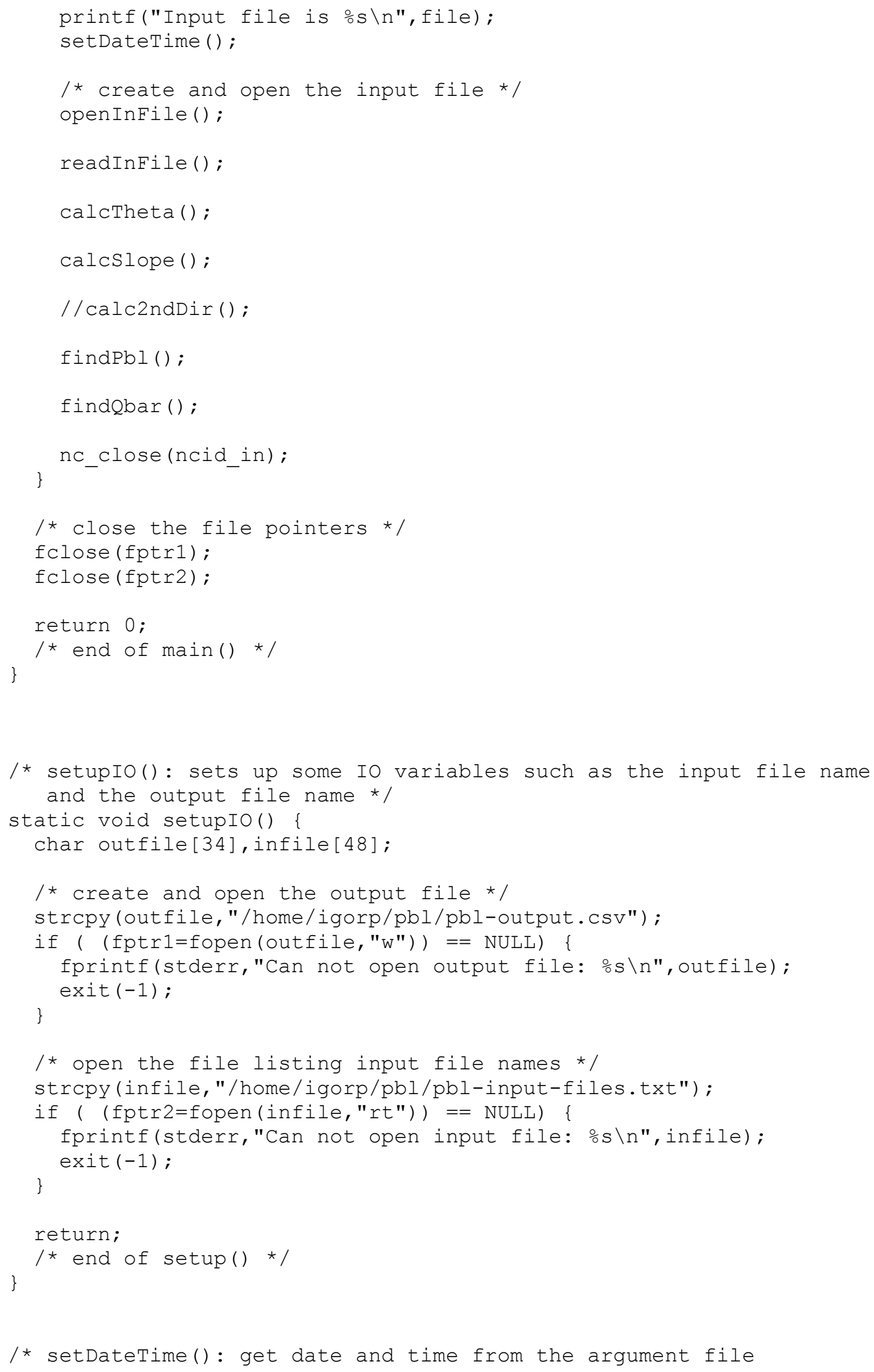




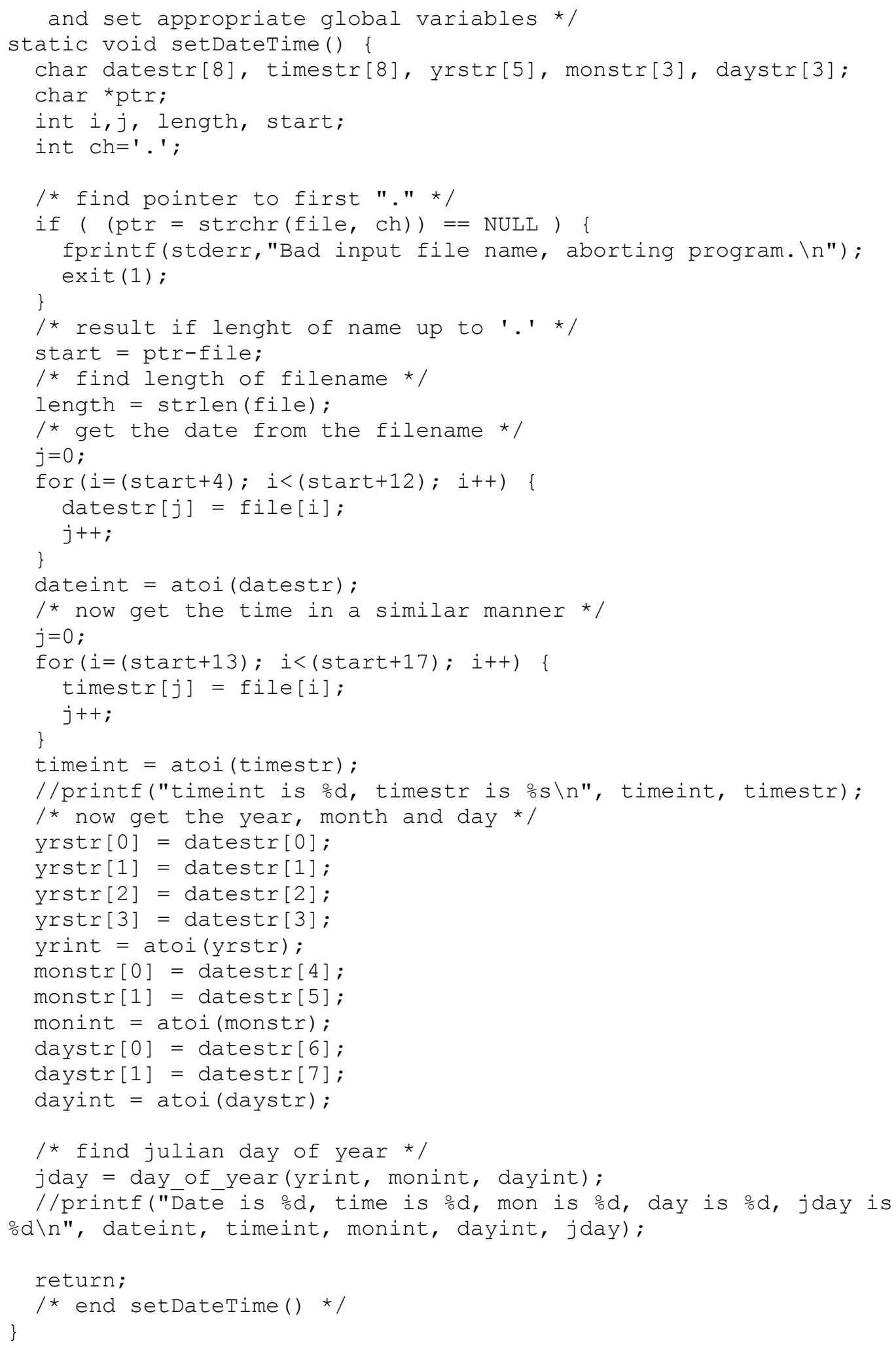




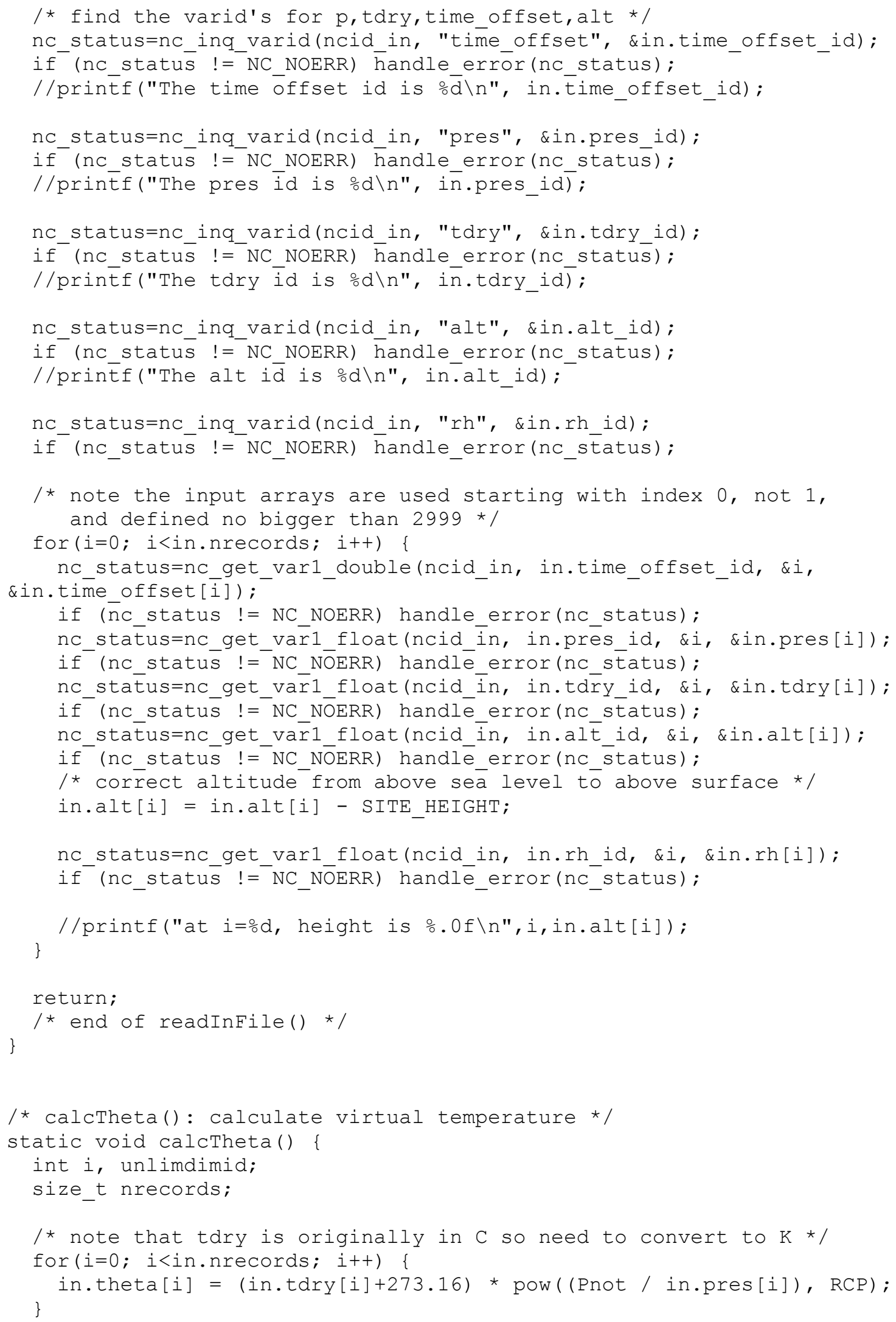




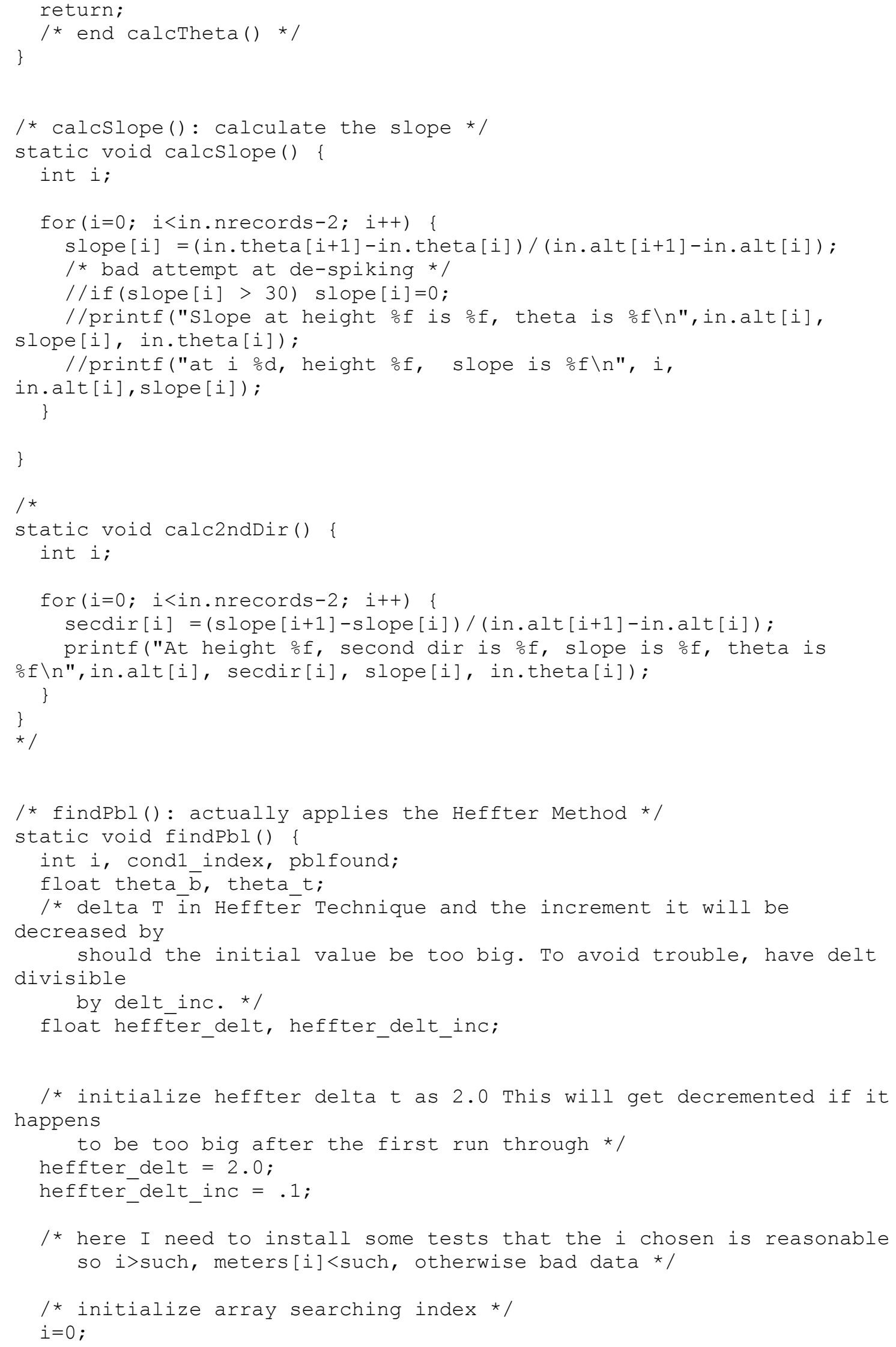




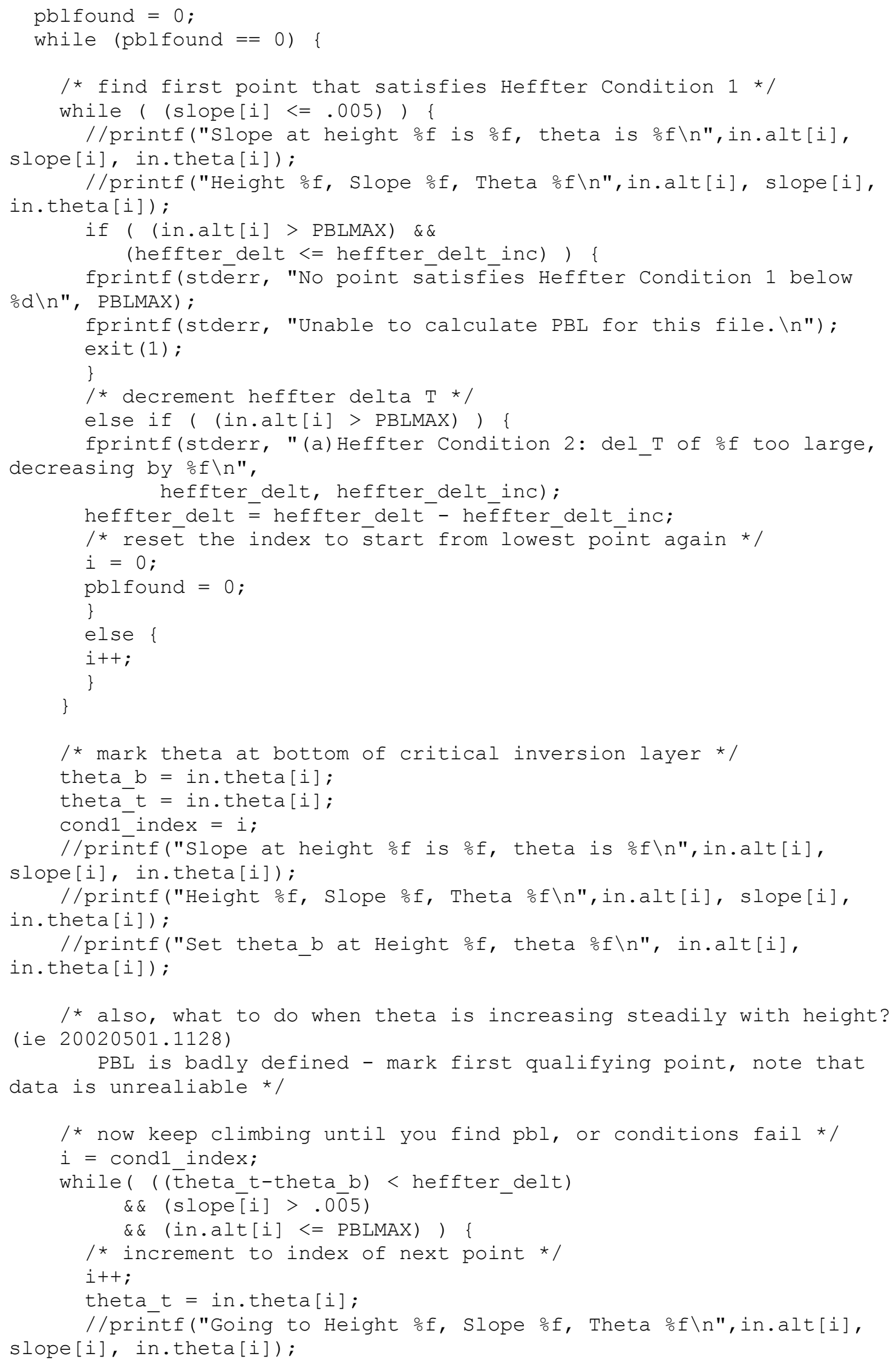




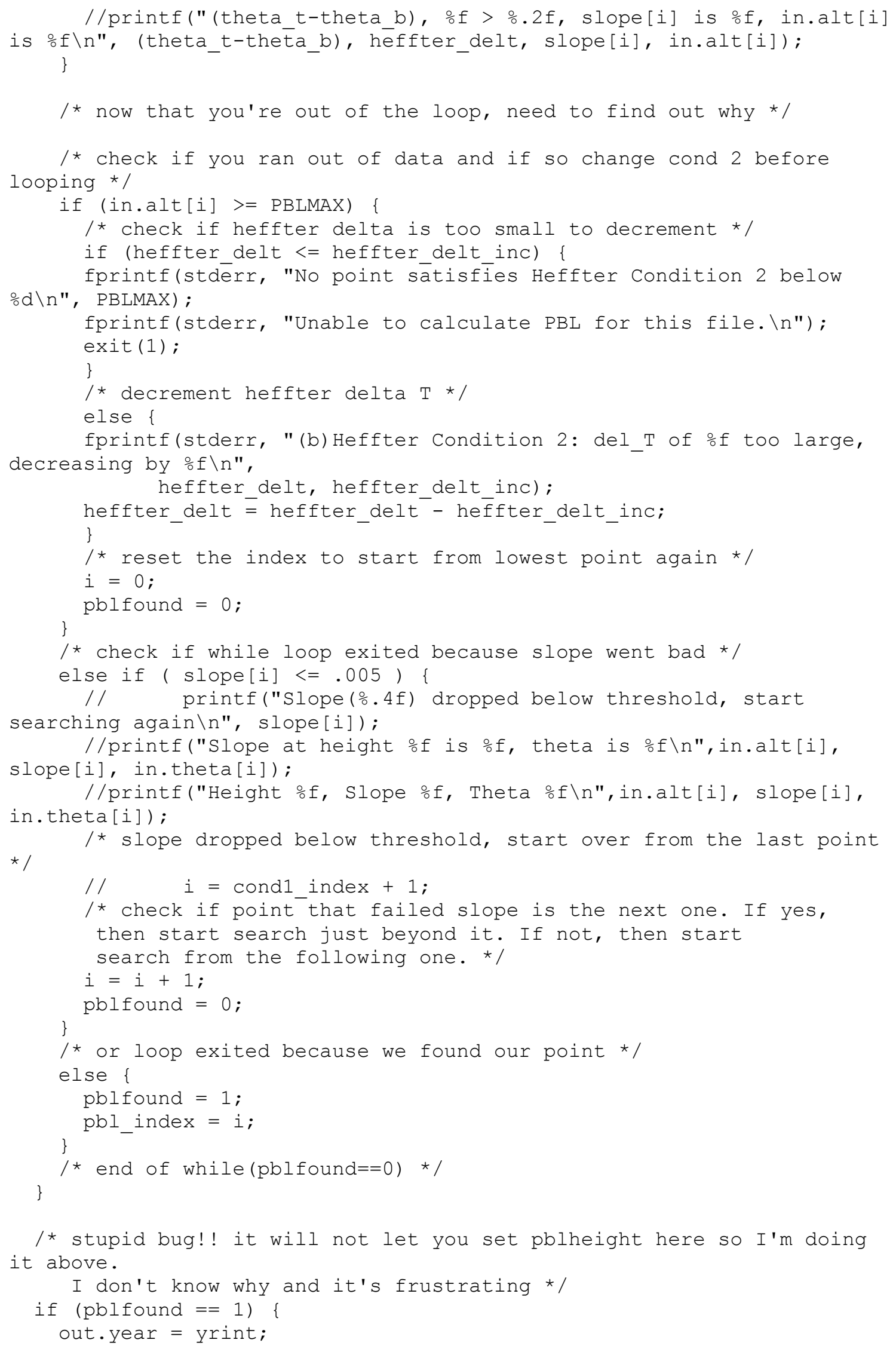




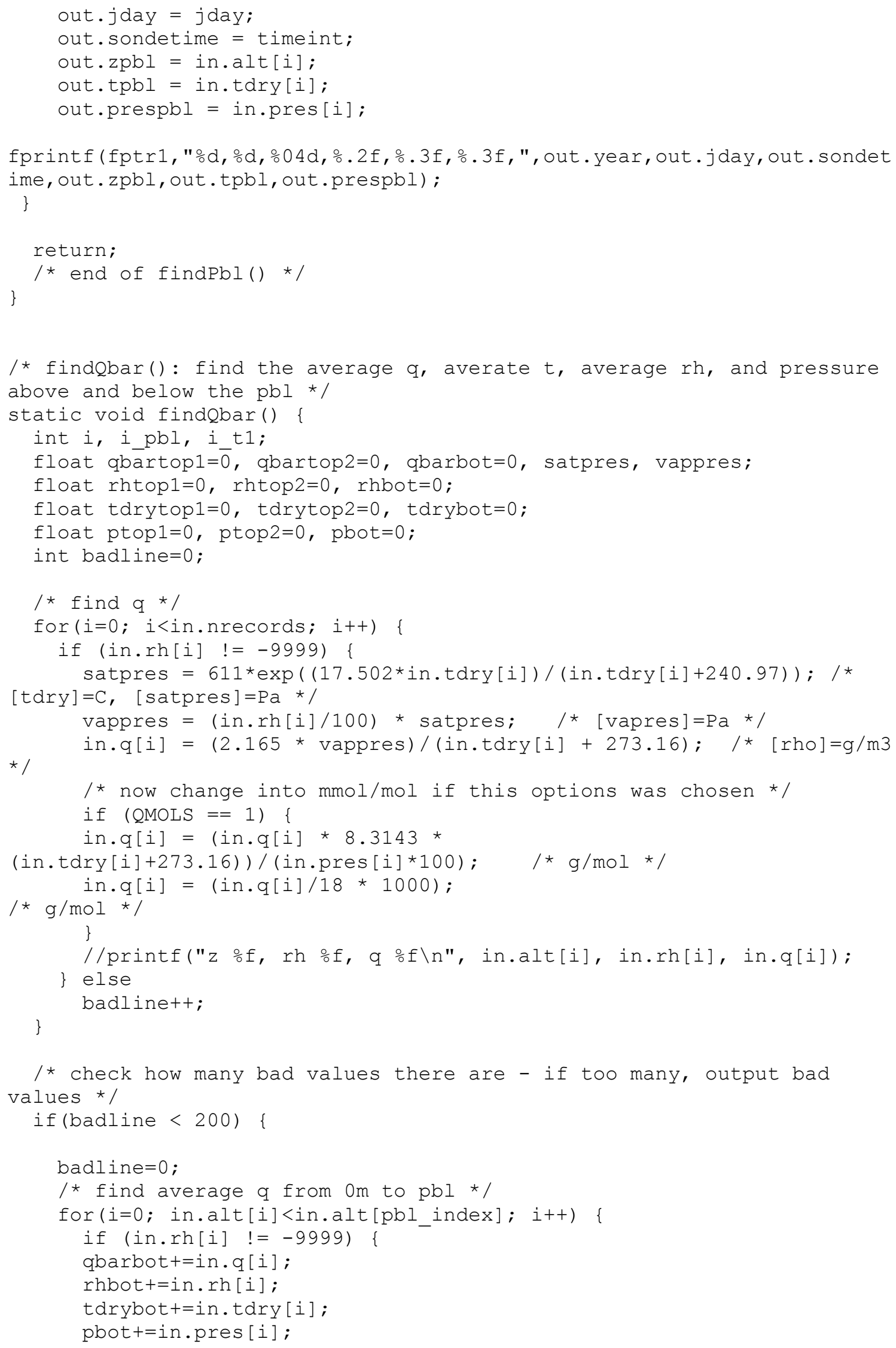




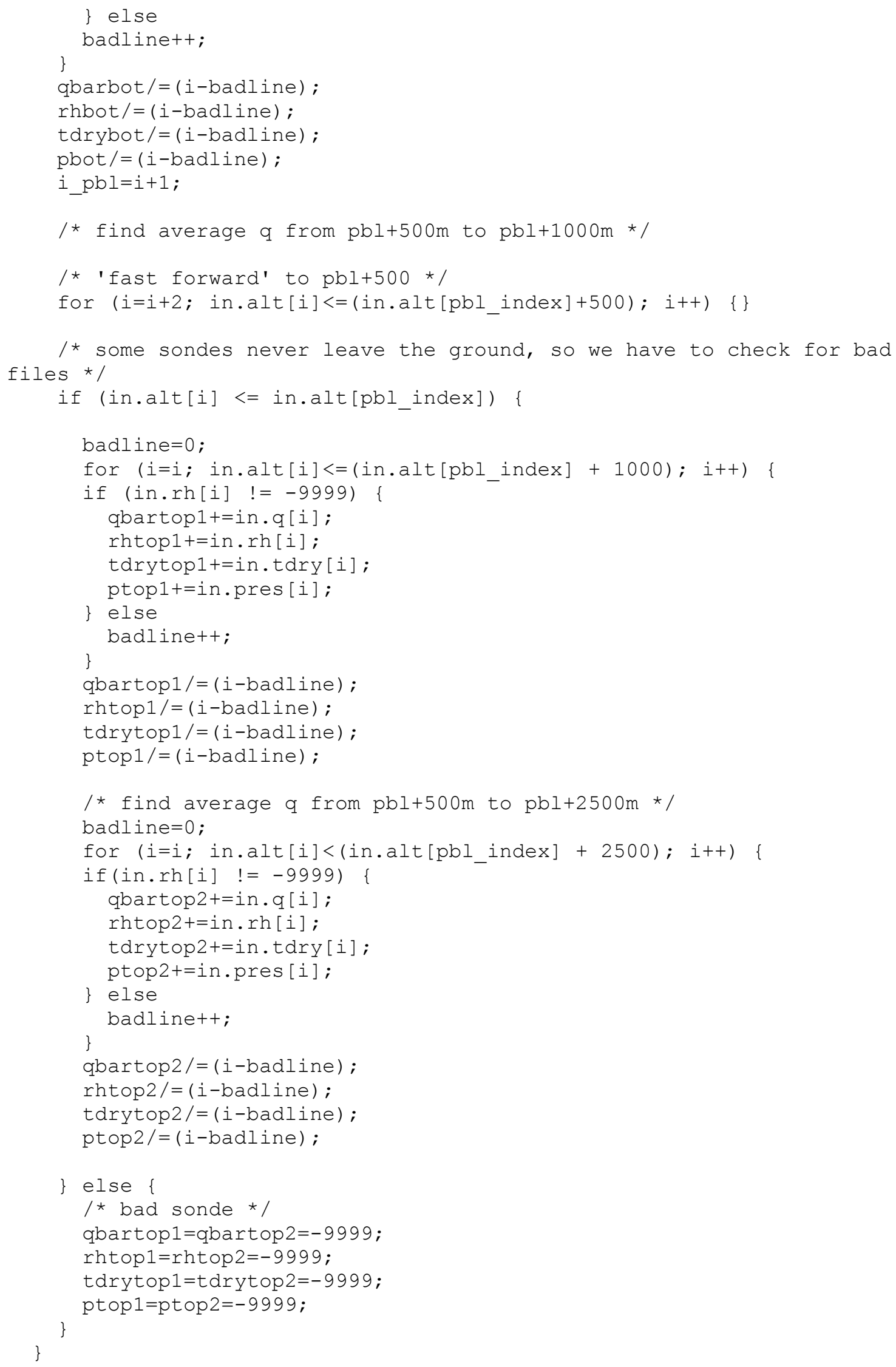




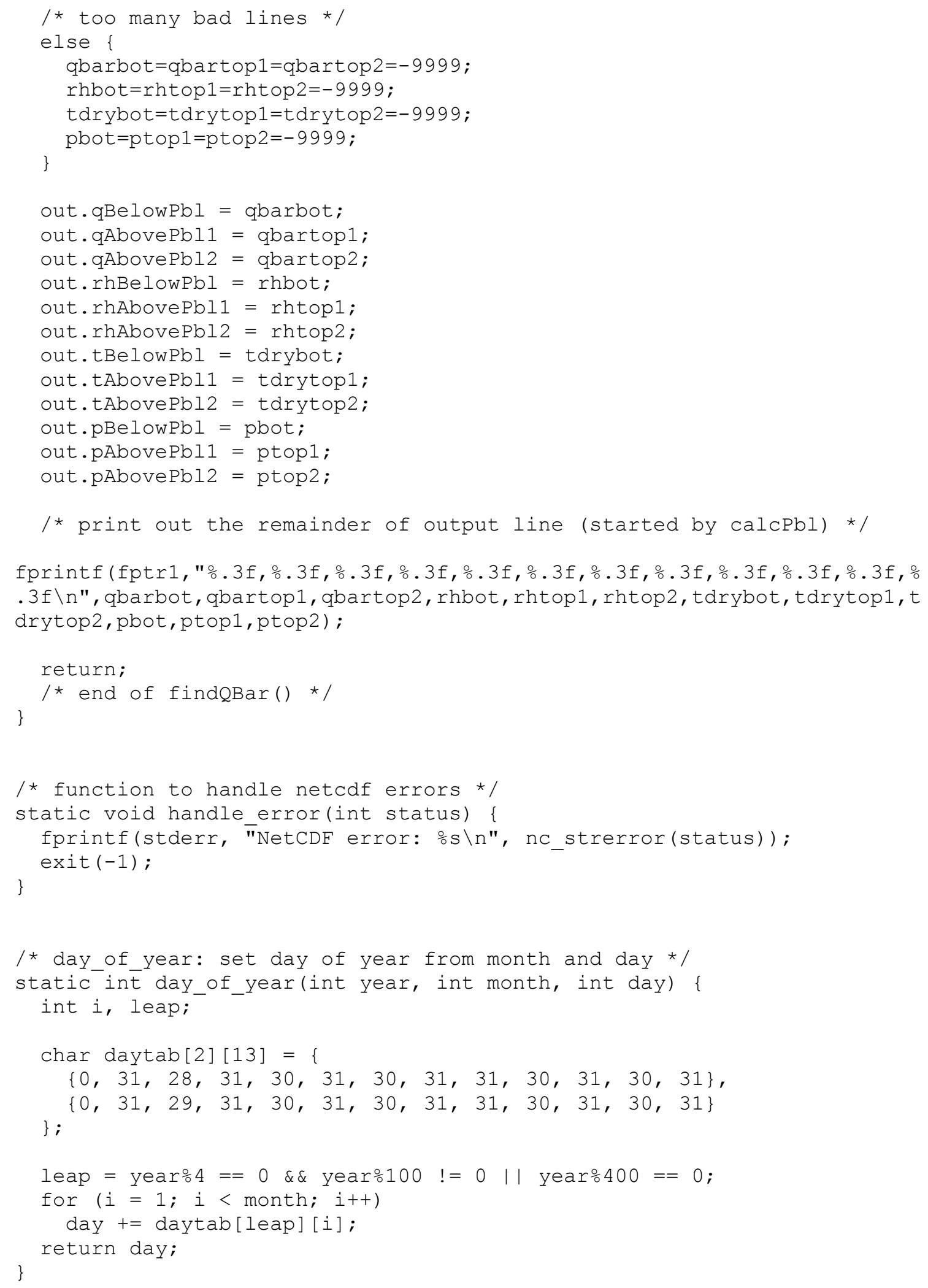

